\title{
Controlled environment agriculture and containerized food production in northern North America
}

\author{
Alex Wilkinson ${ }^{a *}$ and Craig Gerlach ${ }^{\mathrm{b}}$ \\ University of Calgary \\ Meriam Karlsson ${ }^{c}$ \\ University of Alaska Fairbanks
}

Henry Penn ${ }^{\mathrm{d}}$

University of Calgary

Submitted November 12, 2020 / Revised February 9, March 12, and April 6, 2021 / Accepted April 7, 2021 /

Published online August 17, 2021

Citation: Wilkinson, A., Gerlach, C., Karlsson, M., \& Penn, H. (2021). Controlled environment agriculture

and containerized food production in northern North America. Journal of Agriculture, Food Systems, and

Community Development, 10(4), 127-142. https://doi.org/10.5304/jafscd.2021.104.001

Copyright (C) 2021 by the Authors. Published by the Lyson Center for Civic Agriculture and Food Systems. Open access under CC-BY license.

\begin{abstract}
There is an ongoing debate about the role of controlled environment agriculture and containerized food production in local food systems in Northern North American communities. Some critics dismiss these applications as ineffective, arguing that

a* Corresponding author: Alex Wilkinson, Ph.D. Candidate, Research Analyst, School of Architecture, Planning and Landscape, University of Calgary; 2500 University Drive NW; Professional Faculties Building, PF 2182; Calgary, AB T2N 1N4 Canada; +1-403-988-6287; apwilkin@,ucalgary.ca

b Craig Gerlach, Professor, School of Architecture, Planning and Landscape, University of Calgary; scgerlac@ucalgary.ca

c Meriam Karlsson, Professor, Department of Natural Resources and Environment, University of Alaska Fairbanks; mgkarlsson@alaska.edu

d Henry Penn, Ph.D., Arctic Institute of North America, University of Calgary; henry.penn@ucalgary.ca
\end{abstract}

because they marginalize certain populations they do not have a place in northern food systems. However, such critiques are premature and undermine what may prove to be an important and complementary component of local and regional food systems in the north, particularly if designed and implemented in a culturally appropriate and placebased context. Containerized food production can offer enhanced food production capabilities for communities through year-round production. While there are still concerns about proper growing protocols, scalability, output, durability, and

\section{Disclosures}

Alex Wilkinson, Craig Gerlach, and Henry Penn are involved in the ongoing containerized hydroponic system experiment at the Kluane Lake Research Station. The research project is funded entirely by two anonymous donors and the Peter Gilgan Foundation. Collaborations include the broad local community, and specifically local producers and consumers. 
economics, these can be addressed, modified and improved through research and continued applications. New opportunities requiring further exploration in the application of containerized food production systems include, but are not limited to, integrative systems design, the enhancement of community development initiatives, and the integration of the social networks that are necessary for diversified local food production.

\section{Keywords}

Controlled Environment Agriculture, Northern and Subarctic Communities, Containerized Food Production Systems, Food Security, Local Food Production

\section{Introduction}

There is a growing debate about the potential role of controlled environment agriculture (CEA) and containerized food production systems (CFPS) in local food systems (Pinstrup-Andersen, 2018), and these debates are now occurring more specifically in the context of northern communities (Kozachenko, 2020). These discussions are of particular importance for northern communities in Canada and Alaska, where food security is an ongoing challenge (Guo et al., 2015; Inuit Circumpolar Council-Alaska, 2015; Kluane First Nation \& Arctic Institute of Community-Based, n.d., 2016; Tarasuk et al., 2016; Todd, 2010).

Recent criticisms of the role of CEA focuses on an Indigenous context claim that CEA is just another form of outside or "top-down" development (Kozachenko, 2020). While this may be true in some circumstances, we advocate for CEA applications that are relevant for multiple northern rural communities and operations instead, including but not limited to Indigenous communities. Regardless of the community, operation, or system used, all applications must be situated in an appropriate local cultural context and must be designed and implemented in ways that serve the community needs as defined by each community, whether Indigenous, urban, rural, or industrial.

We propose that there is no single or "onesize-fits-all" solution to northern food and nutritional security. We do suggest that CEA remains a potential contribution to a more food-secure future for northern communities, especially in a context of economic, political, and climatic uncertainty (Pinstrup-Andersen, 2018; Treftz \& Omaye, 2016).

The extent to which CEA will be a viable northern food system option going forward depends on a great deal of research and community engagement that remains to be undertaken. With respect to northern communities, we do not view CEA and CFPS as a silver-bullet solution to food and nutritional security. However, we do see the potential for containerized systems to be part of a diversified and integrated food system that has the capacity to meet local and even regional food and nutritional needs. Recognizing that CEA and CFPS will not meet all community food needs, but that they can still play a role in supporting both food and nutritional security is important because they can function as complementary systems that are place-based, culturally appropriate, and designed to meet specific community needs as defined by a community.

In this article, we provide a brief overview of food security issues in northern communities and an overview of CEA and CFPS. We then discuss the advantages and disadvantages of the specific CEA application of CFPS when compared to industrial agriculture and greenhouses and outline the social, economic, and environmental factors that must be considered. Following this, we present some challenges and opportunities for CFPS in the context of future research.

The purpose of this paper is to provide a review of CEA and CFPS in the context of northern applications, to discuss critiques, challenges and drawbacks, advantages and disadvantages, and opportunities, and to provide the basis for understanding what further work is needed to explore successful models going forward. Our focus is on subarctic applications of containerized food production systems, with an emphasis on hydroponic growing methods. We are interested in all northern communities, including but not limited to Indigenous communities, off-grid communities, and industry camps. Definitions for rural and urban vary; for our purposes northern rural communities are disconnected from the road and marine highway systems and/or have a population less than 1,000 (Goldsmith, 2007; Statistics Canada, 2018). 


\section{Food Security in Northern Communities}

Food security in northern communities is challenging due to remoteness, severe weather, and short growing seasons, among other social-ecological factors. Despite these challenges, communities have thrived using subsistence strategies such as hunting, fishing, and community gardens (Gerlach \& Loring, 2013). Livelihoods in the communities have traditionally centered on the harvest of country foods, ${ }^{1}$ although there has been a longterm transition to a cash economy, with increasing reliance on industrially produced, store-bought foods imported from outside and transported long distances.

While commercially available foods provide one measure of food security, the availability and quality of these foods are subject to the vagaries and vulnerabilities of a global food system. Access is dependent on one's ability to pay for storebought foods that do not fulfill many of the roles that country foods play in northern communities (Loring \& Gerlach, 2009). According to Loring and Gerlach (2009), "this transition is having severe consequences for the health of people and for the viability and vitality of rural communities, and in subtle ways that are not always tracked by conventional food security methodologies and frameworks" (p. 466). This dietary or nutritional transition has resulted in diets of poorer nutritional quality, with negative health outcomes related to metabolic and cardiovascular syndromes and diseases, including Type 2 diabetes, coronary heart disease, and colorectal cancer (Hurwitz, 1977; Loring \& Gerlach, 2015). With the ongoing climatic and regulatory impacts on country food and adverse dietary-related health outcomes, the need for local food production strategies that are new and innovative, but still place-based and culturally appropriate, is growing.

\section{Methods}

This review is based on observations made in public news media, informal input from individuals living in Yukon Territory and Alaska, and existing literature on CEA. These sources reveal a variety of perspectives and opinions on the place that CEA has or may have for local food production in northern communities. Given the evolving nature of these technologies and the limited communitybased research that is available, more substantive research on CEA is needed for communities to make informed decisions about how and under what conditions CEA can be applied successfully in northern communities (Gomez et al., 2019; Kozachenko, 2020; Pinstrup-Andersen, 2018). This paper was developed using an extensive but nonsystematic literature review (Berry et al., 2015; Ferrari, 2015). Peer-reviewed journals, books, nonpeer-reviewed literature, and government and industry reports are included in our review.

\section{Overview of Containerized Food Production Systems}

Containerized food production systems are a form of CEA where a container (a shipping container, for example) is repurposed for food production, although in some cases a new container is used due to concerns around the structural integrity of the recycled containers (Newbean Capital, 2017). In these systems, environmental conditions are controlled for optimal plant growth and primarily utilize soilless agriculture techniques (Newbean Capital, 2017; Raviv et al., 2019). CFPS are often used in situations where industrial agricultural production capacity is limited, or where food miles and "price at market" vulnerabilities exist, as is the case for both urban and rural northern communities (Coley et al., 2009; Gómez et al., 2019; Loring \& Gerlach, 2009).

There are numerous techniques and systems that can be used in CFPS, including but not limited to soil-based growing mediums and aquaponics, although hydroponics and aeroponics are probably the most common (Gómez et al., 2019; Newbean Capital, 2017). There are different hydroponic techniques in use now, including the nutrient-film technique, deep-water culture, and aggregate culture. The nutrient-film technique uses a thin film of solution that constantly flows over plant roots, while deep-water culture has plant roots that are constantly submerged in a flowing solution. Aggregate culture has plants in bagged substrates or

1 "Country foods" refer to food harvested from wild animals and plants (Loring \& Gerlach, 2009). 
containers with a drip system for the nutrient solution (Gómez et al., 2019). Aeroponics systems mist roots with a nutrient solution at specific time intervals and volumes (Eigenbrod \& Gruda, 2015). The scale of CFPS systems ranges from small at-home operations up to large-scale container farms or "plant factories" (Gómez et al., 2019; Newbean Capital, 2017).

\section{Containerized Food Production Systems: Advantages and Disadvantages}

Containerized food production systems, greenhouses, and open-field farming each have strengths and weaknesses in relation to operations, resource use, and crop yields, among other factors. Table 1 outlines some key differences between container farms, greenhouses and field farming.

\section{Advantages}

Key advantages of CFPS is season extension, yearround food production, and improved yields per acre or unit when compared to industrial openfield farming and greenhouses. These advantages are amplified when considering the potential of these technologies in northern climates where industrial agricultural opportunities are limited due to short growing seasons, poor soils, and challenging growing conditions (Gómez et al., 2019; Kalantari et al., 2017; Loring \& Gerlach, 2015). CFPS and greenhouses eliminate or significantly reduce the risks associated with extreme weather events such as hail and flooding, and provide some control over growing conditions, including temperature, light, humidity, day length, and carbon dioxide levels to maximize growth rates and yields (Gómez et al., 2019; Raviv et al., 2019).

Risks associated with soil-borne pathogens, among other pests and pathogens, are eliminated or significantly reduced when not using a soilbased medium, and where appropriate cleaning procedures are maintained (Gómez et al., 2019; Raviv et al., 2019).

CFPS minimize water consumption through a variety of controlled irrigation techniques, closedloop irrigation systems, humidity control, and capture of evaporated water for reuse (Raviv et al., 2019). Beyond specific production and resource

\section{Table 1. Comparison of Containerized Food Production Systems (CFPS) Using Hydroponics,} Greenhouse, and Field Farming

Presenting both CFPS and greenhouses demonstrates the differences that can exist between various controlled environment agriculture (CEA) applications.

\begin{tabular}{llll}
\hline & Container Farms & Greenhouse & Field Farming \\
\hline Light source & Electrical lighting & $\begin{array}{l}\text { Sunlight and/or elec- } \\
\text { trical lighting }\end{array}$ & Sunlight \\
\hline Growing season (days/year) & 365 & 365 & Variable \\
\hline Soil Use & Variable & Variable & Yes \\
\hline Harvests per year & $8-12$ for lettuce & $6-7$ for lettuce & Usually 2 for lettuce \\
\hline Water source & Local water network & Local water network & Rainfall and irrigation \\
\hline Water use (gallons/head of lettuce) & 0.3 & 0.3 & 6.5 \\
\hline Electricity use & $\begin{array}{l}\text { High: Lights run 12-20 } \\
\text { hours daily and the heat- }\end{array}$ & $\begin{array}{l}\text { Variable: Lights gener- } \\
\text { ally run more than 2-4 } \\
\text { hours daily and the heat- } \\
\text { ing system is run in }\end{array}$ & $\begin{array}{l}\text { Low } \\
\text { ing system is run in } \\
\text { winter. }\end{array}$ \\
\hline Pest control use & $\begin{array}{l}\text { Variable: Enclosed envi- } \\
\text { ronment and integrated } \\
\text { pest management as } \\
\text { needed }\end{array}$ & $\begin{array}{l}\text { Variable: Enclosed envi- } \\
\text { ronment and integrated } \\
\text { pest management as } \\
\text { needed }\end{array}$ & $\begin{array}{l}\text { Variable: Pesticides, } \\
\text { herbicides, tilling, } \\
\text { mulching, weeding and } \\
\text { integrated pest manage- } \\
\text { ment }\end{array}$ \\
\hline Production (heads of lettuce/acre/year) & 5,000,000 & 1,600,000 & 50,000 \\
\hline
\end{tabular}


consumption advantages, there are benefits related to food production, including individual and community health, and community development potential.

CFPS provide improved capacity for the production of local produce such as leafy greens, which may improve nutritional security, and improve food-related health outcomes in the north (Fallovo et al., 2009; Loring \& Gerlach, 2009). Opportunities for more flexible placement of CFPS in locations close to markets can optimize transport efficiency and reduce the time between harvest and consumption (Gómez et al., 2019; Newbean Capital, 2017). Additionally, these systems can be placed in areas with larger populations and a more accessible and available workforce. A larger population also enhances the potential for utilizing volunteers to reduce production costs and contribute to community development through expanded social networks (Lawson, 2005; Newbean Capital, 2017). While CEA and CFPS vary in complexity and the use of technology, automation is making the systems more user-friendly. These technological advancements allow for community development through increased employment opportunities and business ventures, even for those with limited or no horticultural experience (ColdAcre Food Systems, 2020; Newbean Capital, 2017).

\section{Disadvantages}

CEA and CFPS have limitations in their suitability to support crop production (Sardare \& Admane, 2013). For optimum utilization of space in an enclosed environment, crops are grown vertically in several layers on shelves. Short-stature, fastgrowing plants such as lettuce, leafy greens, and culinary herbs work best in these types of cropping systems. Crops requiring trellising or several months to harvest may be less cost-effective. The controlled sanitized environment of CFPS allows for effective pathogen and pest management. However, a breach allowing pathogen entry into a pest-free environment can result in significant and rapid crop failure (Raviv et al., 2019; Sardare \& Admane, 2013).

The need for energy for heat and power is large in CFPS and greenhouses (Sambor et al.,
2020). Given the current energy demands and issues in the north associated with so many remote communities being reliant on diesel generators, adding yet another energy burden to some communities may prove to be a significant barrier to successful adoption (Cherniak et al., 2015). Note, however, that there are ongoing debates about energy consumption and greenhouse gas emissions of local CFPS food production versus industrial agriculture. When the life cycle assessment (production, processing, distribution, and consumption) is considered, and when the sustainability of local production is compared to that of food imported from industrial operations, the entire life cycle of the food must be considered (EdwardsJones et al., 2008). So far the general consensus is that sustainable food production systems are variable, but most effective when designed in placebased and culturally situated ways (Edwards-Jones et al., 2008; Gómez et al., 2019; Sambor et al., 2020).

For several decades there have been recurring discussions and concerns about CEA with respect to nitrate accumulation and potential health concerns (Sideman, 1999). Nitrate accumulation can be a risk for plants and particularly for leafy greens grown indoors, especially where light levels, nitrogen inputs, or crop storage are not managed appropriately. Nitrate levels exceeding the recommended limits can cause negative health outcomes related to gastrointestinal illness, oxygen transport in infants, and exposure to carcinogens in adults (Santamaria, 2006; Sideman, 1999). An increased accumulation of nitrate in leafy greens tends to be correlated with low light conditions. Earlier production efforts in indoor farming used fluorescent lighting rather than LEDs. With the new LED technology, light levels are now approaching or are similar to those found in a greenhouse or a field during summer conditions. Earlier reported findings of increased nitrate levels may therefore not apply or be accurate for current and more efficient indoor production approaches (Bian et al., 2020). On the other hand, poor management in any type of production system with excessively high or inappropriate fertilizer levels or inadequate climatic conditions can be expected to result in limited production and diminishing nutritional 
quality resulting from excessively high levels of nitrate.

\section{Social, Ecological and Economic Factors to Consider in Containerized Food Production System Projects}

Containerized food production systems can improve the availability, access, variety, and quality of produce in northern regions; however, placebased social-ecological conditions affect the success or failure of a CEA system in each setting (Gómez et al., 2019; Mier y Terán Giménez Cacho et al., 2018). Exploring existing and past local food production systems such as community gardens may help with identifying factors and conditions for successful local food production, in both rural and urban cases (Lawson, 2005). Equally important, exploring local food production as an effective community response to change encourages a systems approach where social, environmental, and economic conditions interact with each other in effective and functional ways (Spring et al., 2019; Walker \& Salt, 2006).

\section{Social and Institutional Factors}

The available research on the social, cultural, economic, and institutional constraints and opportunities for CFPS remains limited, but community gardening, greenhouses, and other local production systems provide details about the social and institutional conditions necessary for successful local food production initiatives (Gómez et al., 2019). Important factors in most cases include the extent of community interest in locally produced food, adequate ownership and/or leadership, education, policies that help rather than hinder (Loring et al., 2011), and strong social networks that foster cooperation and community engagement (Eyssartier et al., 2008; Lawson, 2005; Loring \& Gerlach, 2010).

CFPS and other local food production initiatives require community support, interest, and engagement (Lawson, 2005). Support for local production often results from problems in the existing food system and/or changing social-ecological and climatic conditions, or, sometimes, land-use conflicts (Spring et al., 2019; Wesche \& Chan, 2010). For example, northern communities have limited fresh produce options available, and this selection decreases during the winter. The produce available is often low in nutritional quality, in poor condition with respect to freshness and quality, and expensive (Loring \& Gerlach, 2015). Urban communities may desire local production to decrease food mile vulnerabilities, but another commonly expressed interest in urban communities is the desire to reduce the environmental footprint of their food consumption (Eigenbrod \& Gruda, 2015). Food security issues and environmental sustainability are often leveraged to foster interest and support in local food production (Eigenbrod \& Gruda, 2015; Lawson, 2005; McKay, 2018). While local interest is essential for the success of CFPS, so too is effective leadership and ownership.

Effective leadership is necessary for both the implementation and long-term viability of CFPS. Throughout the history of community gardening, greenhouses, and other local food production strategies, leadership and ownership have come from NGOs, communities, private enterprise, and individuals; the role of government is sometimes effective, and sometimes not (Eyssartier et al., 2008; Gómez et al., 2019; Lawson, 2005). Regardless of who the owner is, committed leadership with the long-term interest and commitment, economic and cultural investment, and viable operations plans are required for the success of local food production (Lawson, 2005). Community gardens have been used in some rural northern settings for generations (Loring \& Gerlach, 2010).

In some circumstances, community gardens have been developed in response to an immediate crisis, with the victory gardens during World War II but one example (Lawson, 2005). The gardens and garden programs that emerged were often implemented without long-term operations in mind and often ceased to exist following the crisis (Lawson, 2005). In other cases, local production from community gardens or greenhouses has been engrained in the community and culture across generations, resulting in both the practices and growing spaces thriving over multiple generations (Eyssartier et al., 2008; Loring \& Gerlach, 2010). While local food production is enhanced through successful leadership, support from governments may help create conditions that encourage the systems to thrive. 
Policy and governmental support are critical for CFPS and other local food production strategies. The global expansion of industrial agricultural and associated practices has resulted in policies that are best suited for large-scale farming systems (Blay-Palmer et al., 2020; Paredes et al., 2019). At a minimum, policy should not be a barrier to CFPS, and in the best circumstances, it should support and/or incentivize individuals or groups to adopt the technology where it is locally appropriate and desired. In 2015, the Milan Urban Food Policy Pact was ratified by mayors from all over the globe, and it explicitly acknowledges the importance that urban centers play in the food system and highlights the need for these centers to actively participate in and promote the transition to sustainable food systems (Blay-Palmer et al., 2020). Top-down endorsements such as this may help lay the foundation for local and regional policies that are supportive, but by themselves are not enough.

Strong social networks are critical for knowledge transmission, and for formal and informal education related to CFPS. Knowledge transmission is critical for success for multiple reasons, including skill development for those adopting new or existing horticultural practices (Eyssartier et al., 2008), as well as communications and education within a community (Coyle \& Ellison, 2017). The community not only serves as a consumer but can be a champion to gain further support for the implementation of CEA (Parmentier, 2014).

Communication and education are important to most producers, although with hydroponically grown produce these may be essential for success. This is the case because some consumers have a limited understanding of the hydroponic growing process and are reluctant to purchase produce from these growing systems as some consider them to be "unnatural" (Coyle \& Ellison, 2017; Gerlach et al., 2011).

\section{Economic Factors}

Economic research on CFPS is also limited, particularly in the context of rural systems and Indigenous communities (Gómez et al., 2019). However, there are some conditions that need to be addressed in most circumstances for successful implementation and operation.
First, there must be adequate funding in place to purchase and install the system, as well as to finance operations (Tokunaga et al., 2015). Secure operational financing is important, as the return on investment of CFPS is slow in many cases (Newbean Capital, 2017). There have been many different approaches to securing funding and launching CFPS systems, with private enterprise being very common, but another promising model is based on social enterprises (Gómez et al., 2019; Lawson, 2005).

Social enterprise models are generally less directly concerned with profitability and return on investment and thus can access diverse funding opportunities through schools, governments, and donors-opportunities that enhance the chances for success (Gómez et al., 2019; Reisman, 2012). As a social enterprise or community-based initiative, CFPS may be better situated to capitalize on the numerous successes that greenhouses and community gardens have experienced so far. These successes include operations that support education and research opportunities in the community, provide leisure activities for community members and volunteers, improve mental health and wellbeing for individuals, and help build stronger community ties (Gómez et al., 2019; Lawson, 2005; Reisman, 2012; Relf \& Lohr, 2003).

Shifting the focus to operations that emphasize community development over profit not only gives CFPS a more diverse range of funding options, but also takes the pressure off system managers with respect to profitability and maximizing sales. While specific evidence of CFPS being used for community development is lacking, local food system development is a common strategy applied for community development. This may include farmers markets, community supported agriculture enterprises, urban farming and agriculture projects, and food hubs (Deller et al., 2017). Different models for CFPS applications should be explored to identify sustainable operations for northern communities that effectively balance community and economic development.

In many cases, locally grown produce such as those from CFPS and other CEA applications are more expensive than produce from industrial agriculture (Coyle \& Ellison, 2017; Gómez et al., 
2019). This factor complicates the application of CFPS in northern communities, although in some cases even a more expensive locally sourced product is preferred to an imported product (EdwardJones, 2008; Gómez et al., 2019). This preference can come from consumers' strong desire to support local production and consumption, a general interest in environmental sustainability, or the lack of other options (Gómez et al., 2019). In those cases where more expensive produce is not feasible for community members to obtain, not-for-profit social enterprise models or alternative communitydriven approaches may develop solutions for CFPS applications that provide locally grown produce that is accessible to all in the community (Gomez et al., 2019; Moragues-Faus, 2019).

When applied in a northern urban setting, CFPS have unique opportunities due to the larger population base, such as partnering with restaurants where they can establish more financially sustainable operations (Gómez et al., 2019). Restaurant partnerships are less viable in rural communities with low populations and few to no commercial restaurants; however, in locations such as Northern Canada, Alaska, or even an island like Hawaii, where most of the food is imported and costs are high, there is an opportunity for CEA and CFPS to be competitive (Tokunaga et al., 2015). Ultimately, the place-based dynamics and community needs will dictate the economic conditions that will be most successful for the operation (Gómez et al., 2019; Tokunaga et al., 2015).

\section{Environmental Factors}

Given that CFPS and greenhouse internal production environments are buffered from the uncertainty of external environmental conditions, system operations may still be affected by external environmental conditions, such as extreme cold or heat influencing the ability to maintain appropriate internal temperature and humidity. The operation of these systems may in turn impact the environment by its footprint on the landscape and through waste products such as nutrient-heavy water, waste crop products, and emissions from diesel generators (Edwards-Jones et al., 2008; Raviv et al., 2019).

The literature relating to northern and coldclimate applications of CEA, and specifically CFPS systems, is still limited, and in some cases, cold climate applications in large urban environments in the northern U.S. such as New York and Boston, or urban centers in Northern Europe have received the most attention (Gentry, 2019; Goldstein et al., 2016). These systems and centers differ in both population demographics and environmental conditions from the northern communities in Canada and Alaska that we are specifically interested in here. However, with increasing interest in indoor and vertical farming across northern Canada, regional systems are now beginning operations (ColdAcre Food Systems, 2020; Gordon, 2021), and these may inform future research and application. Even with the limited data available now, there are a number of known conditions that need to be addressed for successful cold climate implementation.

Northern CFPS must be sufficiently durable to withstand extreme temperature and weather, while still maintaining stable internal temperature and environmental conditions for plant health and growth. Managing the temperature, ventilation, and dehumidification requirements of a system becomes more challenging in northern environments, with significant temperature differences between seasons, meaning that the system design must factor in a wide range of potential outside environmental conditions (Gómez et al., 2019; Raviv et al., 2019; Solvest Inc. \& ColdAcre Food Systems, personal communication, 2019). Maintaining the heating and dehumidification requirements of CFPS in a northern climate requires access to adequate, consistent, reliable, and backup energy sources, as power failure may result in crop loss (Goldstein et al., 2016). The energy intensity of these systems raises questions about sustainability in the context of carbon emissions, particularly as there are still numerous communities in the north that rely on diesel generators (Cherniak et al., 2015; Coley et al., 2009).

While northern urban communities, along with many communities along main highway networks, are connected to the power grid, many remote communities are still completely reliant on diesel generators (Cherniak et al., 2015). This complicates CFPS applications as diesel is not only environmentally unsustainable but is also becoming 
increasingly expensive to operate in remote northern communities (Cherniak et al., 2015).

This raises the question of integrating CFPS with alternative energy sources and developing microgrids to improve system sustainability, and for developing resilient communities. Various renewable energy sources are available, such as solar, wind, and hydropower, with some regions having geothermal potential; however, in most cases, a single renewable source is unlikely to meet all energy needs. This leads to the conclusion that in conjunction with a diversified food system, a complementary diversified energy system would be beneficial and is needed (Cherniak et al., 2015).

Containerized systems, while primarily closed, still generate waste in the form of crop residues and wastewater (Chiew et al., 2015). The waste is often safely discarded, although wastewater can have adverse environmental impacts, particularly at larger scales where it may accumulate, similarly to fertilizer runoff and eutrophication (Goldstein et al., 2016). While this waste product, like many other waste products, is perceived as a burden, there may be an opportunity for repurposing it, such as wastewater being utilized for liquid fertilizer in open field gardens or greenhouses, and waste plant material being composted (Chiew et al., 2015). Local communities need capacity, education, interest, and knowledge to manage these issues.

\section{Major Challenges for Successful Containerized Hydroponic Food Production Systems in Northern Communities}

Containerized production has the potential for improving food and nutritional security in the context of changing social-ecological systems, although there are a significant number of challenges and uncertainties facing its widespread adoption, which is why further work is needed. Improved growing protocols for a diverse range of culturally preferred crops, scalability, yield output, durability, and economics are some areas that need to be addressed (Gómez et al., 2019; Newbean Capital, 2017).

\section{Growing Protocols}

There are useful demonstrations of a wide range of crop production outputs in controlled environments, including but not limited to leafy greens, tomatoes, various berries, root crops such as potatoes and carrots, and medicinal plants (Asaduzzaman et al., 2013; Ritter et al., 2001; Treftz \& Omaye, 2016). Growing protocols for many crops are still limited, particularly in soilless applications, and while produce such as potatoes and carrots can be grown hydroponically, the growth rate, nutritional value, or aesthetic quality may vary (Asaduzzaman et al., 2013; Ritter et al., 2001). Based on the authors' personal communications with hydroponic growers in Yukon, these crops can be grown, but it is difficult and the results are sometimes less than optimal due to small yields and inconsistent results (Solvest Inc. \& ColdAcre Food Systems, personal communication, 2019).

Given the long history of gardening in northern Indigenous communities with an emphasis on root crops, coupled with the challenges of outdoor growing in northern climate and weather situations, there is still a preference for root crops, especially among Indigenous Elders (Loring \& Gerlach 2010). Before CEA will be widely adopted and accepted, research identifying suitable growing techniques for these crops is needed.

\section{Scalability and Outputs}

Containerized systems are efficient in terms of crop yield per acre for some crops, like leafy greens, although scalability and produce output are still challenging. Every community's needs and expectations for food production from CFPS vary, in terms of both quantity and types of produce. To address these different local and regional expectations, applications of CFPS must be flexible and embrace customizable designs beyond traditional greenhouse and hydroponic production methods (Gómez et al., 2019; Newbean Capital, 2017).

The production outputs claimed in some literature (Coyle \& Ellison, 2017) and industry reports (Newbean Capital, 2017) have been criticized for being overestimated and difficult to replicate as each system has different crop mixes, environmental conditions, scheduling, growing options, and production methods (Newbean Capital, 2017). Realistic output projections for real-world growing scenarios and protocols are necessary for communities and individuals looking to adopt CFPS as an effective response to social-ecological change. 


\section{Durability}

CEA applications, specifically CFPS, face concerns about structure durability in northern and other harsh climates (Raviv et al., 2019). A strength of CFPS is the potential to reuse and repurpose existing structures such as shipping containers for environmental sustainability and cost-effectiveness (Newbean Capital, 2017). However, structure strength and stability may be a concern. In many circumstances, the reused structures have already experienced adverse weather conditions and deterioration. These issues confirm the validity of concerns about their long-term durability in rural cold climate conditions, particularly where many communities lack the capacity to repair these systems in the event of a failure. The travel and delivery of these repurposed units to remote communities may contribute to further deterioration (Newbean Capital, 2017; Raviv et al., 2019). Ultimately, any repurposed units require an extensive assessment to ensure structural integrity.

\section{Economics}

Research from the container farm industry has shown that less than half of CFPS are profitable (Newbean Capital, 2017). Some advocates state that the entry costs for CFPS can be relatively low (Newbean Capital, 2017), and this may be the case when compared to purchasing a conventional farm in many parts of the world. However, it is clear that fixed capital costs and ongoing maintenance and operational costs for northern communities may prove to be too expensive (Banerjee \& Adenaeuer, 2014; Gómez et al., 2019; Newbean Capital, 2017). The financial challenges may also be compounded for northern remote locations due to increased delivery costs for the equipment and supplies (Newbean Capital, 2017; Tokunaga et al., 2015). This potentially poor economic outlook for CFPS strongly conditions the outlook for social enterprise and community-based business models, and for well-integrated and diversified approaches (Gómez et al., 2019). In addition to community development approaches, subsidies and grants may provide a feasible approach to CFPS projects in northern Canada where existing subsidy programs like Nutrition North exist, which subsidizes the cost of expensive imported food (Galloway, 2017); exploring the use of subsidies to increase local production may lead to a more sustainable approach.

\section{Opportunities for Successful CFPS in Northern Communities}

Situating CFPS within the context of effective community responses to change, combined with literature about successful community gardening and greenhouse initiatives, can provide useful insights into potential opportunities for CFPS to become more widely adopted and to have more consistent success. The two opportunities discussed below are related to integrative systems design solutions that include food production and energy and water systems, and an increased emphasis on the social-ecological network that encompasses food production. These opportunities are discussed in the context of a recently launched research experiment being conducted at the Kluane Lake Research Station, Yukon, Canada.

\section{Kluane Lake Research Station: An Off-grid Containerized Food Production Experiment}

The Kluane Lake Research Station (KLRS) in Southwest Yukon, Canada, is operated by the Arctic Institute of North America and is the home of a new fully funded off-grid containerized food production experiment. The authors are involved in the experiment, and we are working closely with a wide range of community members in Yukon on the project, including producers and consumers. The KLRS experiment serves as the basis for applied research on CEA applications in northern remote communities, may help to address some of the concerns related to CEA applications, and will provide communities with valuable information to make an informed decision about implementing a CEA or CFPS application. The community support received so far is for the experiment at the research station. As research results continue to come in, local communities will be in a better position to make their own evaluations about whether these systems are applicable for their community.

The purpose of this research is to provide communities across the north with relevant information to make informed decisions about the role these systems may or may not play in their community. While a research station is not a perfect proxy 
for a rural community, it offers some similar conditions that a community would operate under, including remoteness and an off-grid power supply. Researching some of the community-specific conditions will be supported through further community engagement and with the support of the project's advisory board, which includes representatives from across Yukon, including but not limited to horticultural experts, container farmers, First Nations communities, urban and rural communities, and government agencies. Advisory board members were identified through existing relationships and partnerships with communities and community organizations around the Yukon.

This advisory board is responsible for helping guide the research on this project to ensure that experiments and research reflect the true wants and needs of the communities in the region. The community engagement aspects of the project include conducting surveys and interviews with communities in relation to CFPS, food distribution, and developing education and training materials for $\mathrm{K}$ 12 curriculum and employment purposes.

Ultimately, this experiment aims to develop knowledge and provide information so northern communities can make informed decisions about how and if CEA can support their community. In addition to the ongoing experiment, future research associated with this program includes a meta-analysis of CEA and CFPS literature that will serve as a follow-up to this nonsystematic review.

\section{Integrated Systems Design}

Integrating CFPS with other food production systems may help address real and perceived disadvantages, increase the likelihood of CFPS being successful for local and regional community lead food production, and hopefully improve food and nutritional security in remote and northern communities.

An integrated approach is being applied to the experiment at KLRS. In this experiment, a CFPS has been installed off-grid with solar energy and a battery bank for energy storage, with backup diesel power (Allford, 2017). The integration with renewable energy sources will help reduce power costs for the system, reduce overall diesel reliance, and improve the sustainability of CFPS (Cherniak et al.,
2015; Sambor et al., 2020). The integration of energy and food systems is also being explored in Sweden, where researchers have explored the integration of vertical hydroponic systems and district heating applications in an urban setting (Gentry, 2019).

Beyond energy systems, there are opportunities to integrate CFPS with water systems. In the case of the KLRS experiment, a small-scale off-grid treatment system is being installed to treat wastewater at the research station. While this does not currently integrate with the CFPS, it supports resilient community design, and there may be future opportunities to better integrate the system components into a more functional whole. Additionally, there is evidence that exploring integrative and diversified approaches in one location improves efficiency and access to resources such as water and electricity and may lower overall costs for each system component (Davis et al., 2016).

Diversified food systems that include various local food production sources provide a more resilient and sustainable system that can more effectively meet food and nutrition requirements and have increased protection from food system failures or issues that occur in regional and global food systems (Blay-Palmer et al., 2020). Exploring the integration between and among various local food production systems may well improve overall local system operation. For example, wastewater from hydroponic systems can be repurposed as a liquid fertilizer for greenhouses or open field gardens, eliminating the need to dispose of the wastewater (Chiew et al., 2015). Additionally, soilbased production can help address challenges associated with CFPS related to a variety of crops that are not always grown successfully in controlled environments using hydroponic methods, such as carrots or potatoes. Successful integration across various systems will require multiple individuals to be involved and a full understanding of the social-ecological network that controls the local food system (Davis et al., 2016; Janssen et al., 2006).

\section{Community Development and Social Networks in Diversified Local Food Production}

The research program at KLRS is being completed 
in close collaboration with a broad local community that includes producers and consumers in the region to not only ensure the success of this individual experiment, but also to develop protocols and strategies for successful applications across the region. Our emphasis is on finding the best way to develop a system that is most useful for remote communities. There is limited research on the social and institutional factors of CFPS, and the ability to effectively address food security and dietary-related health issues, particularly in the context of rural northern communities, remains a work in progress, recent criticism of the approach notwithstanding (Kozachenko, 2020).

Given the limited research, the concerns about the relevance or efficacy of CFPS in addressing food security and responding to social-ecological change in northern communities may be premature, particularly when it is understood that local food systems are place-based and contextual (BlayPalmer et al., 2020; Loring \& Gerlach, 2010). Based on this understanding, it is critical to not consider any food system in isolation from the larger food network or social-ecological system; rather this must be seen as a component that interacts with many other system components, including the relationship to local, regional, and global systems and their existing production and distribution networks.

Understanding that many successful community gardens and greenhouses have not been "silver bullet" solutions but are complementary components to an existing food system is paramount in reframing how CFPS is perceived in communities (Lawson, 2005). Emphasizing CFPS as a community-based initiative that is one component of a diverse food system that can support sustainable community development and effective responses to changing social-ecological dynamics may result in more successful applications of the technology (Blay-Palmer et al., 2020; Walker \& Salt, 2006).

As with greenhouse and community gardens, CFPS can improve community support through educational initiatives for youth and adults, create a social and cultural hub through volunteering opportunities and community events, and engage individuals in agricultural and horticultural activi- ties who would otherwise not have these opportunities (Gómez et al., 2019; Lawson, 2005). Achieving these outcomes requires perspectives that focus on the interwoven social-ecological network associated with local food production, instead of a myopic focus on the technology and a technological solution to what is fundamentally a cultural, social, and ecological problem Janssen et al., 2006). One positive side effect is the building of strong networks within the community. This can create opportunities for further food system innovation through the integration of diverse knowledge sources, and for collaborative opportunities that can inform flexible, place-based, and integrative systems designed to meet local needs (Spring et al., 2019; Loring \& Gerlach, 2010).

The new research program at KLRS involves collaboration that supports a better understanding of the dietary preferences of the region, along with the development of growing protocols and research output for selected produce. This collaboration should lead to a better understanding of the dynamic social-ecological network that affects local food production, building strategies for both understanding and navigating the system (Berkes et al., 2008).

\section{A Final Note}

Given the ongoing and projected challenges with existing food systems, change is needed at local, regional, and global scales to support diversified and resilient food systems that help rather than hinder food security and nutritional security (Spring et al., 2019). We note above that responding to these changes does not include developing "silver-bullet" solutions, but rather focusing on developing place-based strategies and responses that are flexible and diversified. Based on this, the claims that CFPS cannot and should not support food security in northern communities are premature and counter-productive. CFPS may fit into a diversified food system at local and regional scales, supporting improved food and nutritional security and complementing other system components by optimizing resource and infrastructure use, and by promoting local food production and community development. 


\section{Acknowledgments}

We would like to thank Marian Zlomislic in the University of Calgary Development Office for her support in working with foundations and getting funding for the Kluane Lake Research Station experiment. We would also like to thank Brittany Webber, the agricultural operations manager at
Kluane Lake Research Station, and Maribeth Murray, executive director of the Arctic Institute of North America, for her continued support of this research. Last, we would like to thank Carl Burgess of Whitehorse, YT, for his ongoing support of the project and insights in this field.

\section{References}

Allford, J. (2017, May 19). Kluane Lake Research Station tests Yukon's first bydroponic growing system [Press release]. University of Calgary. https://www.ucalgary.ca/news/kluane-lake-research-station-tests-yukons-first-hydroponic-growing-system

Asaduzzaman, M., Kobayashi, Y., Mondal, M. F., Ban, T., Matsubara, H., Adachi, F., \& Asao, T. (2013). Growing carrots hydroponically using perlite substrates. Scientia Horticulturae, 159, 113-121. https://doi.org/10.1016/j.scienta.2013.04.038

Banerjee, C., \& Adenaeuer, L. (2014). Up, up and away! The economics of vertical farming. Journal of Agricultural Studies, 2(1), 40-60. https://doi.org/10.5296/jas.v2i1.4526

Berkes, F., Colding, J., \& Folke, C. (2008). Navigating social-ecological systems: Building resilience for complexity and change: Cambridge University Press.

Berry, E. M., Dernini, S., Burlingame, B., Meybeck, A. \& Conforti, P. (2015). Food security and sustainability: Can one exist without the other?. Public Health Nutrition, 18(13), 2293-2302. https://doi.org/10.1017/S136898001500021X

Bian, Z., Wang, Y., Zhang, X., Li, T., Grundy, S., Yang, Q., \& Cheng, R. (2020). A review of environmental effects on nitrate accumulation in leafy vegetables grown in controlled environments. Foods, 9(6), Article 732. https://doi.org/10.3390/foods9060732

Blay-Palmer, A., Conaré, D., Meter, K., Di Battista, A., \& Johnston, C. (Eds.). (2020). Sustainable food system assessment: Lessons from global practice. Routledge. https://doi.org/10.4324/9780429439896

Cherniak, D., Dufresne, V., Keyte, L., Mallett, A. \& Schott, S. (2015). Report on the state of alternative energy in the Arctic. Sustainable Energy Research Centre, School of Public Policy and Administration, Carlton University. https:/ / curve.carleton.ca/08515c6b-3b39-4c41-ad7b-2c6306cf0379

Chiew, Y. L., Spångberg, J., Baky, A., Hansson, P.-A., \& Jönsson, H. (2015). Environmental impact of recycling digested food waste as a fertilizer in agriculture-A case study. Resources, Conservation and Recycling, 95, 1-14. https://doi.org/10.1016/j.resconrec.2014.11.015

ColdAcre Food Systems. (2020). Home. Retrieved from https://www.coldacre.ca

Coley, D., Howard, M., \& Winter, M. (2009). Local food, food miles and carbon emissions: A comparison of farm shop and mass distribution approaches. Food Policy, 34(2), 150-155. https://doi.org/10.1016/i.foodpol.2008.11.001

Coyle, B. D., \& Ellison, B. (2017). Will consumers find vertically farmed produce “out of reach"? Choices, 32(1), 1-8. http://dx.doi.org/10.22004/ag.econ.253382

Davis, S. C., Kauneckis, D., Kruse, N. A., Miller, K. E., Zimmer, M., \& Dabelko, G. D. (2016). Closing the loop: Integrative systems management of waste in food, energy, and water systems. Journal of Environmental Studies and Sciences, 6, 11-24. https://doi.org/10.1007/s13412-016-0370-0

Deller, S. C, Lamie, D., \& Stickel, M. (2017). Local foods systems and community economic development. Community Development , 48(5), 612-638. https://doi.org/10.1080/15575330.2017.1373136

Edwards-Jones, G., Milà i Canals, L., Hounsome, N., Truninger, M., Koerber, G., Hounsome, B., Cross, P., York, E. H., Hospido, A., Plassmann, K., Harris, I. M., Edwards, R. T., Day, G. A. S., Tomos, A. D., Cowell, S. J., \& Jones, D. L. (2008). Testing the assertion that 'local food is best': The challenges of an evidence-based approach. Trends in Food Science \& Technology, 19(5), 265-274. https://doi.org/10.1016/j.tifs.2008.01.008

Eigenbrod, C., \& Gruda, N. (2015). Urban vegetable for food security in cities. A review. Agronomy for Sustainable Development, 35(2), 483-498. https://doi.org/10.1007/s13593-014-0273-y 
Eyssartier, C., Ladio, A. H., \& Lozada, M. (2008). Cultural Transmission of traditional knowledge in two populations of north-western Patagonia. Journal of Ethnobiology and Ethnomedicine, 4, Article 25. https://doi.org/10.1186/1746-4269-4-25

Fallovo, C., Rouphael, Y., Cardarelli, M., Rea, E., Battistelli, A., \& Colla, G. (2009). Yield and quality of leafy lettuce in response to nutrient solution composition and growing season. Journal of Food, Agriculture, and Environment, 7(2), 456-462. https://www.wflpublisher.com/Abstract/1695

Ferrari, R. (2015). Writing narrative style literature reviews. Medical Writing 24(4), 230-235. https://doi.org/10.1179/2047480615Z.000000000329

Galloway, T. (2017). Canada's northern food subsidy Nutrition North Canada: A comprehensive program evaluation. International Journal of Circumpolar Health 76(1), Article 1279451. https://doi.org/10.1080/22423982.2017.1279451

Gentry, M. (2019). Local heat, local food: Integrating vertical hydroponic farming with district heating in Sweden. Energy, 174, 191-197. https://doi.org/10.1016/i.energy.2019.02.119

Gerlach, S. C., \& Loring, P. A. (2013). Rebuilding northern foodsheds, sustainable food systems, community well-being, and food security. International Journal of Circumpolar Health, 72, Article 21560. https://doi.org/10.3402/ijch.v72i0.21560

Gerlach, S. C., Loring, P. A., Turner, A., \& Atkinson, D. E. (2011). Food systems, environmental change, and community needs in rural Alaska. In A. L. Lovecraft \& H. Eicken (Eds.), North by 2020: Perspectives on Alaska's Changing Social-Ecological Systems (pp. 89-109). University of Alaska Press.

Goldsmith, S. (2007). The remote rural economy of Alaska. Institute of Social and Economic Research, University of Alaska Anchorage. https:// citeseerx.ist.psu.edu/viewdoc/download?doi=10.1.1.576.5503\&rep=rep1\&type=pdf

Goldstein, B., Hauschild, M., Fernández, J., \& Birkved, M. (2016). Testing the environmental performance of urban agriculture as a food supply in northern climates. Journal of Cleaner Production, 135, 984-994. https://doi.org/10.1016/j.jclepro.2016.07.004

Gómez, C., Currey, C. J., Dickson, R. W., Kim, H.-J., Hernández, R., Sabeh, N. C., Raudales, R. E., Brumfield, R. G., Laury-Shaw, A., Wilke, A. K., Lopez, R. G., \& Burnett, S. E. (2019). Controlled environment food production for urban agriculture. HortScience, 54(9), 1448-1458. https://doi.org/10.21273/HORTSCI14073-19

Gordon, S. (2021). Working with Northern communities [Blog post]. The Growcer. https://www.thegrowcer.ca/blog/working-with-northern-communities

Guo, Y., Berrang-Ford, L., Ford, J., Lardeau, M.-P., Edge, V., Patterson, K., IHACC Research Team, \& Harper, S. L. (2015). Seasonal prevalence and determinants of food insecurity in Iqaluit, Nunavut. International Journal of Circumpolar Health, 74(1), Article 27284. https://doi.org/10.3402/ijch.v74.27284

Hurwitz, B. (1977). Subsistence foods: A physician's perspective on the D-2 land proposal. Alaska Medicine, 19(5), 60-62.

Inuit Circumpolar Council-Alaska (2015). Alaskan Inuit food security conceptual framework: How to assess the Arctic From an Inuit perspective [Technical Report]. https://arctichealth.org/en/viewer?file $=\% 2 \mathrm{fmedia} \% 2 \mathrm{fpubs} \% 2 \mathrm{f} 295946 \% 2 \mathrm{fInuitCircumpolarCouncilFoodSecurity-}$ FullAssessmentReport.pdf\#phrase $=$ false

Janssen, M. A., Bodin, Ö., Anderies, J. M., Elmqvist, T., Ernstson, H., McAllister, R. R. J.,Olsson, P., \& Ryan, P. (2006). Toward a network perspective of the study of resilience in social-ecological systems. Ecology and Society, 11(1), Article 15. https://doi.org/10.5751/ES-01462-110115

Kalantari, F., Mohd Tahir, O., Lahijani, A. M., \& Kalantari, S. (2017). A review of vertical farming technology: A guide for implementation of building integrated agriculture in cities. Advanced Engineering Forum, 24, 76-91. https://doi.org/10.4028/www.scientific.net/AEF.24.76

Kluane First Nation \& Arctic Institute of Community-Based Research. (n.d.). Nourishing Our Future: 2015 Community Food Sharing Project. https://www.aicbr.ca/kfn-project

Kluane First Nation \& Arctic Institute of Community-Based Research. (2016). Nourishing Our Future: Building on Kluane First Nations Community food security strategy \& youth engagement in traditions related to fisheries and fish health in Kluane Lake. https://www.aicbr.ca/s/FINALKFNNourishingOurFutureReportPhase2 Aug2016 FINAL5b25dcompressed.pdf 
Kozachenko, C. (2020). Perceptions of controlled environment agriculture: Food security and Northern communities [Master's thesis]. University of Guelph, Ontario, Canada. http://hdl.handle.net/10214/18004

Lawson, L. J. (2005). City bountiful: A century of community gardening in America: University of California Press.

Loring, P. A., \& Gerlach, S. C. (2009). Food, culture, and human health in Alaska: An integrative health approach to food security. Environmental Science \& Policy 12(4), 466-478. https://doi.org/10.1016/i.envsci.2008.10.006

Loring, P. A., \& Gerlach, S. C. (2010). Outpost gardening in interior Alaska: Food system innovation and the Alaska native gardens of the 1930s through the 1970s. Ethnobistory, 57(2), 183-199. https://doi.org/10.1215/00141801-2009-060

Loring, P. A., \& Gerlach, S. C. (2015). Searching for progress on food security in the North American North: A research synthesis and meta-analysis of the peer-reviewed literature + supplementary appendix. ARCTIC, 68(3), $283-406$. https://doi.org/10.14430/arctic4509

Loring, P. A., Gerlach, S. C., Atkinson, D. E., \& Murray, M. S. (2011). Ways to help and ways to hinder: Governance for effective adaptation to an uncertain climate. ARCTIC, 64(1), 73-88. https://doi.org/10.14430/arctic4081

McKay, J. (2018, June 1). Whitehorse company pitches off-grid hydroponics to improve Northern food security. CBC News. https://www.cbc.ca/news/canada/north/cropbox-yukon-food-security-1.4686857

Mier y Terán Giménez Cacho, M., Giraldo, O. F., Aldasoro, M., Morales, H., Ferguson, B. G., Rosset, P., Khadse, A., \& Campos, C. (2018). Bringing agroecology to scale: Key drivers and emblematic cases. Agroecology and Sustainable Food Systems, 42(6), 637-665. https://doi.org/10.1080/21683565.2018.1443313

Moragues-Faus, A. (2019). Action research as a tool to measure progress in sustainable food cities: enacting reflexive governance principles to develop indicators. In A. Blay-Palmer, D. Conaré, K. Meter, A. Di Battista \& C. Johnston (Eds.), Sustainable food system assessment (pp. 111-129). Routledge.

Newbean Capital. (2017). The promise and peril of container farming.

Paredes, M., Cole, D. C., Boada, L., \& Berti, P. R. (2019) Assessing responsible food consumption in three Ecuadorian city regions. In A. Blay-Palmer, D. Conaré, K. Meter, A. Di Battista \& C. Johnston (Eds.), Sustainable food system assessment (pp. 195-215). Routledge.

Parmentier, S. (2014). Scaling-up agroecological approaches: What, why and how? Oxfam-Solidarity. https://www.fao.org/fileadmin/templates/agphome/scpi/Agroecology/Agroecology Scalingup agroecology what why and how -OxfamSol-FINAL.pdf

Pinstrup-Andersen, P. (2018). Is it time to take vertical indoor farming seriously?. Global Food Security, 17, $233-235$. https://doi.org/10.1016/j.gfs.2017.09.002

Raviv, M., Lieth, J. H., \& Bar-Tal, A. (2019). Soilless culture: Theory and practice. Elsevier.

Reisman, A. (2012). A greenhouse in the city: The uses and roles of community-oriented urban greenhouses [Doctoral dissertation]. Tufts University, Boston, Massachusetts.

Relf, P. D., \& Lohr, V. I. (2003). Human issues in horticulture. HortScience, 38(5), 984-993. https://doi.org/10.21273/HORTSCI.38.5.984

Ritter, E., Angulo, B., Riga, P., Herrán, C., Relloso, J., \& San Jose, M. (2001). Comparison of hydroponic and aeroponic cultivation systems for the production of potato minitubers. Potato Research, 44, 127-135. https://doi.org/10.1007/BF02410099

Sambor, D. J., Wilber, M., Whitney, E., \& Jacobson, M. Z. (2020). Development of a tool for optimizing solar and battery storage for container farming in a remote Arctic microgrid. Energies 13(19), Article 5143. https://doi.org/10.3390/en13195143

Santamaria, P. (2006). Nitrate in vegetables: Toxicity, content, intake and EC regulation. Journal of the Science of Food and Agriculture, 86(1), 10-17. https://doi.org/10.1002/jsfa.2351

Sardare, M. D., \& Admane, S. V. (2013). A review on plant without soil - Hydroponics. International Journal of Research in Engineering and Technology, 2(3), 299-304. https://doi.org/10.15623/ijret.2013.0203013

Sideman, E. (1999). Nitrate accumulation: A growers' guide. Maine Organic Farmers and Gardeners. https://www.mofga.org/resources/season-extension/nitrate-accumulation/ 
Spring, A., Skinner, K., Simba, M., Nelson, E., Baltzer, J., Swanson, H., \& Turetsky, M. (2019). Taking care of the land: An interdisciplinary approach to community-based food systems assessment in Kakisa, Northwest Territories, Canada. In A. Blay-Palmer, D. Conaré, K. Meter, A. Di Battista, \& C. Johnston (Eds.), Sustainable food system assessment (pp. 42-65). Routledge.

Statistics Canada. (2018). Rural area (RA). https://www150.statcan.gc.ca/n1/pub/92-195-x/2011001/geo/ra-rr/ra-rr-eng.htm

Tarasuk, V., Mitchell, A., \& Dachner, N (2016). Household food insecurity in Canada, 2014. Food Insecurity Policy Research (PROOF). https://proof.utoronto.ca/

Todd, Z. S. C. (2010). Food security in Paulatuk, NT_-Opportunities and challenges of a changing community economy [Master's thesis]. University of Alberta. https://doi.org/10.7939/R3W69D

Tokunaga, K., Tamaru, C., Ako, H., \& Leung, P. (2015). Economics of small-scale commercial aquaponics in Hawaici. Journal of the World Aquaculture Society, 46(1), 20-32. https://doi.org/10.1111/jwas.12173

Treftz, C., \& Omaye S. T. (2016). Hydroponics: Potential for augmenting sustainable food production in non-arable regions. Nutrition \& Food Science, 46(5), 672-684. https://doi.org/10.1108/NFS-10-2015-0118

Walker, B., \& Salt, D. (2006). Resilience thinking: Sustaining ecosystems and people in a changing world. Island Press.

Wesche, S. D., \& Chan, H. M. (2010). Adapting to the impacts of climate change on food security among Inuit in the Western Canadian Arctic. Ecohealth, 7, 361-373. https://doi.org/10.1007/s10393-010-0344-8 